\title{
The ongoing debate over fetal anatomic surveys in the first trimester: a matter of timing?
}

\author{
This article was published in the following Dove Press journal: \\ Research and Reports in Neonatology \\ II March 2015 \\ Number of times this article has been viewed
}

\section{Carlo Luchi}

Department of Experimental and Clinical Medicine, University of Pisa, Pisa, Italy
Correspondence: Carlo Luchi Department of Experimental and Clinical Medicine, Section of Gynecology and Obstetrics, University of Pisa, Via Roma, 67 56100, Pisa, Italy Tel +39050992604

Email c.luchi@unipi.it
Abstract: Both new technologies and fetal medicine development have led the perinatologist to a new way of "seeing" the fetus in order to improve maternal and neonatal outcome. Thanks to the inversion of pyramid care, the first trimester anatomical fetal survey has become the moment to identify patients at specific risk of pregnancy complications. This review is based on the latest Literature that prove how ultrasound fetal anatomy can be related not only with chromosomal abnormalities, but also with structural defects, like cardiovascular ones, with developing brain injuries or with developing syndromic diseases; furthermore pregnancy complications like preeclampsia and preterm birth have been considered too.

Keywords: chromosomal abnormalities, cardiovascular diseases, first trimester, ultrasound, fetal anomalies

\section{Introduction}

The last decade can be considered one of the "changing" periods both for obstetrics and prenatal ultrasound. Ranging from nuchal translucency (NT) to the inversion of pyramid care, a new concept has been introduced of first trimester ultrasound as the moment in which pregnancies at a specific risk can be identified. ${ }^{1}$

Probably due to the new technologies offered by ultrasound machines that provide the use of imaging software for bidimensional, three and fourth dimensional, the use of probes both abdominal and transvaginal reaching high frequencies up to $18 \mathrm{Mhz}$, the exploration of fetal ultrasound has become more and more detailed, with highest sensitivity at 11-14 weeks. Also, operators' knowledge has been stimulated by the new way of "seeing" the fetus that is now shown in a very different way compared to few years ago.

Surely, NT must be considered the revolutionary parameter: before its evaluation, first trimester ultrasound was considered as the only moment for assessing fetal viability and gestational age. Kypros Nicolaides set a "challenge" in the 1990s when he considered the fetus to be the first "parameter" to evaluate for chromosomal anomalies instead of maternal age and many biochemical tests that were proposed in those years. He focused his attention on small details that could have been related to Down syndrome like NT and later to nasal bone, proposing an algorithm that could indicate a patient's risk for chromosomal anomalies, which is used worldwide today.

Fetal ultrasound at first trimester has now become the so-called "nuchal scan" because in these years, nuchal measurement has reached a very important significance for many fetal diseases - not only for chromosomal defects, but also for genetic syndromes, congenital cardiac anomalies, and maternal infections. 
Now, performing the nuchal scan allows the operator the possibility to explore the fetus in a very complete way and in particular to analyze many anatomical features which until now had remained undiscovered. In a recent review, detection rate has been estimated between $18 \%-71 \%,{ }^{2,3}$ and Luchi et al established that this would be more accurate if ultrasound is performed at 12-13 weeks compared to 11 weeks. ${ }^{2,3}$

Surely, the second trimester ultrasound remains the gold standard for detection of fetal structural defects, but the first trimester can be considered, actually, the crucial point where many diseases can be identified and where the pregnant woman can be directed toward specific care pathways. ${ }^{4}$

In this review I will not take into consideration the various anatomical districts, now widely debated, but only the most current studies involving specific fetal anatomical details that can be related to development of future diseases (Table 1).

\section{Face: cleft lip and palate and micrognathia}

Prenatal detection of midface fetal anomalies in the first trimester is still a diagnostic challenge, but up until today, many studies have been focused on the fetal profile.

Cleft lip and palate are the most common midfacial malformations. Cleft lip occurs due to a failure of fusion of the medial nasal processes and maxillary swellings, while cleft palate develops due to a fusion defect of both palatine processes. The fact that approximately $80 \%$ of cleft lip cases are associated with cleft palate and their association with other anomalies, such as trisomy 13,18 , and 21 , achondroplasia, atrial/ventricular septal defect, persistent ductus arteriosus, and many others, is well known. ${ }^{5,6}$ Recently, Sepulveda et al described a sonographic technique that can be useful in screening for this malformation at 11-13 weeks of gestational age by visualizing the "retronasal triangle" during assessment of the fetal face in the coronal plane. ${ }^{7}$ The triangle is made up by the simultaneous viewing of the two frontal processes of the maxilla and the primary palate, which, at this early gestational age shows a higher echogenicity than the surrounding tissues (Figure 1).

The advent of the three-dimensional ultrasound has allowed us to examine primary and secondary palate in the first trimester. Martinez-Ten et al showed that three-dimensional ultrasound in high-risk women resulted in a detection rate of $100 \%$ for cleft lip, $86 \%-90 \%$ for cleft lip/palate and $0 \%-89 \%$ for cleft palate only. ${ }^{8}$

In order to allow an accurate diagnosis in the first trimester and considering the close association between cleft lip/ palate and other malformations, some ultrasound markers
Table I Anatomical details and their correlation with the possible development of fetal diseases

\begin{tabular}{|c|c|}
\hline \multicolumn{2}{|l|}{ Face } \\
\hline Retronasal triangle & Not evident in case of cleft lip and palate \\
\hline 3D ultrasound & $\begin{array}{l}\text { Allows to examine primary and } \\
\text { secondary palate }\end{array}$ \\
\hline Mandibular gap & Absent in case of micrognathia \\
\hline \multicolumn{2}{|l|}{ Central nervous system } \\
\hline Internal translucency & Absent in case of spina bifida \\
\hline BSOB & Decreased in open spina bifida \\
\hline BSOB-brain stem ratio & Higher in open spina bifida \\
\hline BPD & $\begin{array}{l}\text { Below the fifth percentile in } 50 \% \text { of } \\
\text { fetuses with spina bifida }\end{array}$ \\
\hline Cerebrospinal fluid & Reduced in case of spina bifida \\
\hline Butterfly sign & Absent in case of holoprosencephaly \\
\hline Bat-like choroid plexus & Trisomy 22 \\
\hline Dangling choroid plexus & Ventriculomegaly \\
\hline $\begin{array}{l}\text { Lateral ventricles and } \\
\text { choroid plexus area }\end{array}$ & Both reduced in trisomy 21 \\
\hline CLR & $\begin{array}{l}\text { Smaller in fetuses with trisomy } 13 \text { and } \\
18 \text { normal in trisomy } 21\end{array}$ \\
\hline $\begin{array}{l}\text { Cisterna magna's } \\
\text { thickness }\end{array}$ & $\begin{array}{l}\text { Below the fifth percentile in case of } \\
\text { spina bifida, over the } 95 \text { th percentile in } \\
\text { case of Blake's pouch cyst }\end{array}$ \\
\hline \multicolumn{2}{|l|}{ Congenital heart defects } \\
\hline Nuchal translucency (NT) & NT over $99^{\circ}$ percentile \\
\hline \multicolumn{2}{|l|}{ Ductus venosus } \\
\hline Flow & $\begin{array}{l}\text { Reversed in case of chromosomal } \\
\text { abnormalities and minor cardiac defects }\end{array}$ \\
\hline Absence & $\begin{array}{l}\text { Related to chromosomal aberrations, } \\
\text { absence of the portal vein and to adverse } \\
\text { outcomes such as in utero heart failure }\end{array}$ \\
\hline \multicolumn{2}{|l|}{ Tricuspid valve flow } \\
\hline Regurgitation & $\begin{array}{l}\text { Related to major chromosomal } \\
\text { abnormalities and congenital heart } \\
\text { defects (CHD) in euploid fetuses }\end{array}$ \\
\hline \multicolumn{2}{|l|}{ Hepatic artery } \\
\hline PSV & $\begin{array}{l}\text { Increased in trisomy } 2 \mathrm{I} \text {; in euploid } \\
\text { fetuses high PSV is associated with } \\
\text { tricuspid regurgitation and reversed } \\
\text { a-wave in the ductus venosus }\end{array}$ \\
\hline $\mathrm{PI}$ & Decreased in trisomy 21 \\
\hline ARSA & $\begin{array}{l}\text { Present in about } 5 \%-25 \% \text { of fetuses } \\
\text { with trisomy } 21 \text { as an independent sign }\end{array}$ \\
\hline \multicolumn{2}{|l|}{ Cervical length } \\
\hline $\begin{array}{l}\text { Cervico-isthmic } \\
\text { complex length }\end{array}$ & $\begin{array}{l}\text { No difference between delivery before } \\
\text { and after } 34 \text { weeks }\end{array}$ \\
\hline Endocervical length & Shorter in case of PTD \\
\hline
\end{tabular}

Abbreviations: 3D, three dimensional; CLR, choroid plexus to lateral ventricle areas ratio; PSV, peak systolic velocity; PI, pulsatility index; ARSA, aberrant right subclavian artery; BSOB, brain stem and the occipital bone; BPD, biparietal diameters; PTD, preterm delivery.

should be detected by skilled operators, including increased NT thickness, abnormal profile, and structural anomalies involving other systems.

Coronal plane view is probably important to detect another face malformation like micrognathia. The early 
detection of this condition is a desirable clinical goal, as it can lead to identification of many genetic syndromes and chromosomal disorders, such as trisomy 18 and triploidy. Sepulveda et al have noticed that under the retronasal triangle there is a characteristic separation between the right and left bodies of the mandible, which they have defined as the "mandibular gap", absent in fetuses with severe micrognathia (Figure 2). ${ }^{9}$ Nevertheless, more studies will be needed to confirm the diagnostic value of the retronasal view.

\section{Central nervous system}

Open spina bifida (myelomeningocele) is the most common neural tube defect, and its incidence range is about $1 / 1,000$ deliveries. It results from an early incomplete closure of the caudal region of the neural tube during embryogenesis, which causes an elongation of the midbrain and a herniation of the cerebellum and medulla toward the foramen magnum. ${ }^{10}$

Typical spina bifida signs, such as the scalloping of the frontal bone ("lemon sign"), BPD smaller than expected, "hanging" choroid plexuses in the dilated lateral ventricles, curved shape of the cerebellum ("banana sign"), and dysraphic defect of the spine, are detectable at mid-gestation. ${ }^{11-13}$ In the last few years, many studies have been conducted with the aim to find easily identifiable markers during the first trimester.

In 2009, Chaoui et al suggested, as a marker, the internal translucency, a term that indicates the fourth ventricle of the fetal brain in the mid-sagittal plane, which is absent in those fetuses with spina bifida due to the caudal displacement of the middle brain structure (Figure 3). ${ }^{14}$

Lachmann et al studied the mid-sagittal plane and they observed that, in some cases of open spina bifida, the diameter of the brain stem appeared to be increased, whereas the distance between the brain stem and the occipital bone

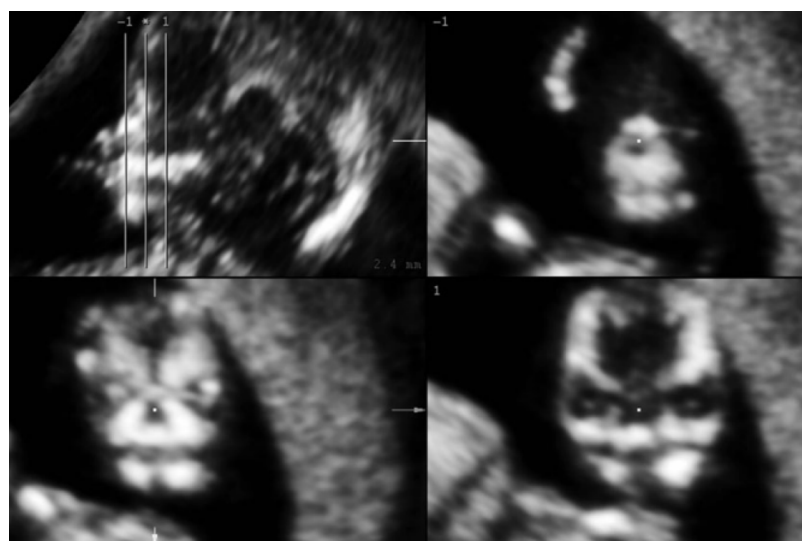

Figure I Parallel coronal views of the fetal face showing the retronasal triangle. appeared to be decreased and the brain stem to brain stem and the occipital bone ratio is substantially higher in comparison with normal fetuses. ${ }^{15}$

Bernard et al evaluated BPD at 11-14 weeks, showing that $50 \%$ of cases of open spina bifida have a BPD below the fifth percentile. Subsequently, this group showed that the combination of first trimester BPD below the fifth centile with maternal serum markers a-fetoprotein and free $\beta$-human chorionic gonadotropin (hCG), improves the detection rate for open spina bifida to $70 \%$, with a fixed false positive rate of $10 \% .^{16}$

In 2012, Loureiro et al studied the cerebral ventricular system and its morphological change in case of spina bifida at 11-13 weeks' gestation. They found that cerebrospinal fluid is substantially reduced with a decrease in the area of the lateral ventricles and in the diameter of the roof of the third ventricle, the diameter of the aqueduct of Sylvius, and the diameter of the fourth ventricle. ${ }^{17}$

Other less common abnormalities of the fetal spine, such as abnormal curve of the spine, structural anomalies of the vertebrae, or caudal regression syndrome can be detected during a first trimester scan in the most severe cases or when they are associated with other major abnormalities, otherwise it still requires a second trimester scan of the fetal spine to detect minor spinal defects due to the poor ossification and size of the fetal spine in early gestation. ${ }^{18}$

Choroid plexuses can be studied in a cross-sectional view of the fetal brain, and their appearance is known as the "butterfly sign". In 2004, Sepulveda et al studied the value of choroid plexus dysmorphology as a screening tool for first trimester sonographic diagnosis of holoprosencephaly

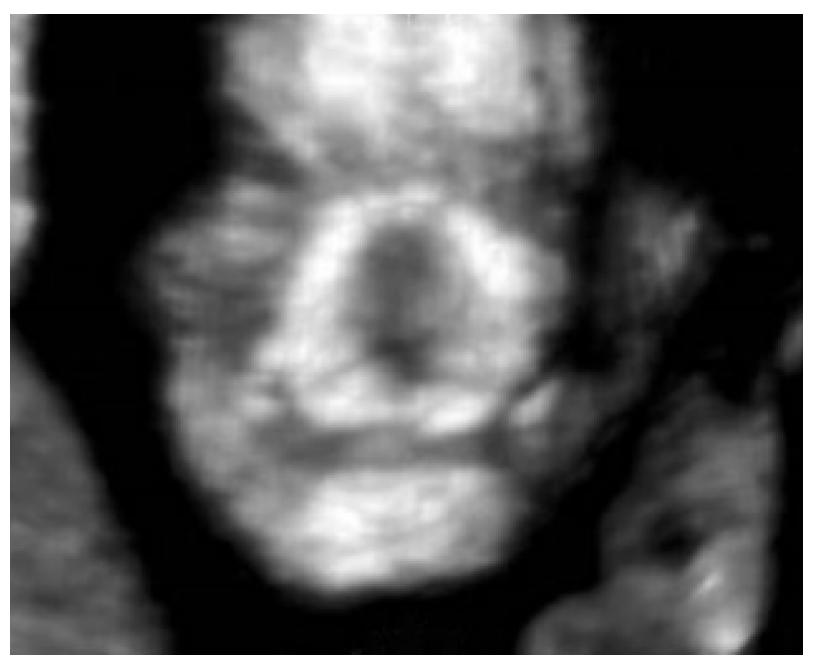

Figure 2 First trimester fetus with micrognathia: this image shows the absence of the mandibular gap. 


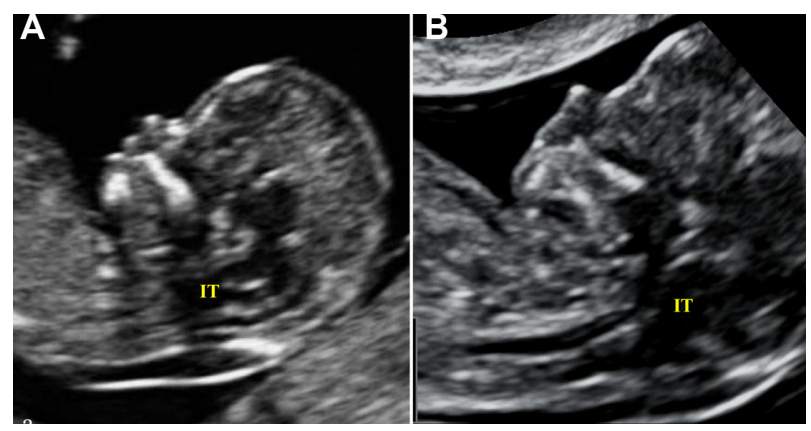

Figure $\mathbf{3}$ Internal translucency (IT) in normal fetus (A) and in a fetus affected by spina bifida (B).

in a high-risk population and they noticed that the absence of the butterfly sign can be related to this pathological condition. $^{19}$

An anomalous "bat-like" configuration of the choroid plexus in the first trimester has been associated with fetal chromosomal abnormality, in particular with trisomy 22 (Figure 4). ${ }^{20}$

In 1991, Bronshtein and Ben-Shlomo studied the dismorphism of choroid plexus by transvaginal sonography, and they noticed that in a case of ventriculomegaly, the choroid plexuses do not occupy the entire space. ${ }^{21}$ "Ventriculomegaly" and "hydrocephalus" are both terms used to describe a dilatation of lateral ventricles, but they should be distinguished from one another, because in hydrocephalus there is an increased intracranial pressure that can be absent in ventriculomegaly. ${ }^{22}$

Causes of ventriculomegaly include aneuploidies, genetic syndromes, viral infections, and central nervous system processes. ${ }^{23}$ In early pregnancy, large lateral ventricles occupy most of the intracranial space, and they are characteristic of normal brain morphology as shown in many studies. ${ }^{24}$ Van Zalen-Sprock et al argued the possibility of detecting ventriculomegaly by "dangling choroid plexus", which is defined as a choroid plexus far from the medial wall of the lateral ventricle. ${ }^{25}$

Loureiro et al studied the relationship between lateral ventricles and aneuploidies, focusing on choroid plexus to lateral ventricle areas ratio: in fetuses with trisomy 18 and trisomy 13 , this ratio is significantly smaller than in the euploid fetuses; meanwhile, the choroid plexus to lateral ventricle areas ratio has the same value in a fetus with trisomy 21 compared with euploid fetuses but, in this case, both lateral ventricle and choroid plexus areas are significantly smaller. ${ }^{26}$

Furthermore, the cisterna magna complex can be evaluated: this is a fluid collection posterior to the cerebellum that can be seen as an echo-free area. Enlarged cisterna magna is an isolated feature not usually related to any pathology, but there might be an increased risk for chromosomal anomaly if it is found in association with others markers. ${ }^{27}$

Garcia-Posada et al studied the thickness of the cisterna magna in a mid-sagittal view, routinely used for NT assessment. A thickness below the fifth percentile is related to spina bifida, while a spread over the 95 th percentile can be related to posterior fossa anomalies such as Blake's pouch cyst even if further studies are due to confirm this result in a prospective large series (Figure 5). ${ }^{28}$

\section{Congenital heart defects}

Congenital heart defects (CHDs) account for one-third of all congenital anomalies and are the leading cause of infant mortality due to birth defects for which corrective or palliative surgery is required after birth. ${ }^{29,30}$ The accuracy of first trimester screening for heart defects in the low risk population has been the subject of many studies over the last 15 years. ${ }^{31-33}$ With improved technology, it has become feasible to obtain images of the fetal heart in the first trimester, with visualization of both the four heart chambers and the outflow tracts of the great vessels being performed from as early as 11 weeks' gestation. ${ }^{34}$

Westin et al defined how to perform correct first trimester fetal echocardiography. ${ }^{35}$ In a recent review, Kahil and Nicholaides have reported that the early detection rate, with ultrasound scan, for the most common cardiac abnormalities ranges from around 51\% for hypoplastic left heart to $16 \%$ for coarctation of the aorta, $18 \%$ for tetralogy of Fallot, and transposition of the great arteries. ${ }^{36}$ Another study conducted by Syngelaki et al in 2011, involving 44,859 singleton pregnancies, reported that the detection rate of

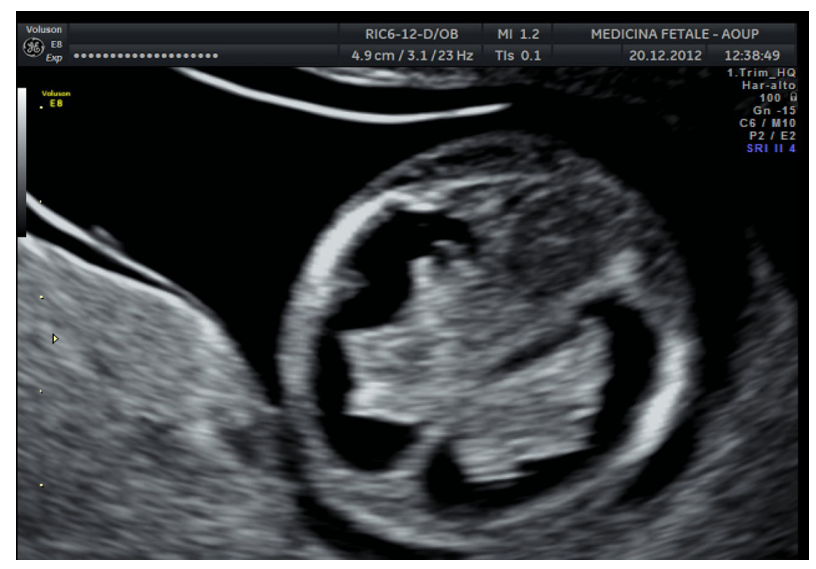

Figure 4 "Bat-like" choroid plexus. 
major CHDs was 34\%, of which around half of the cases were double outlet right ventricle, hypoplastic left heart, and transposition of the great arteries; around one-third of the cases were atrioventricular septal defect, coarctation of the aorta, tetralogy of Fallot, and pulmonary atresia. ${ }^{37}$ Some cardiac abnormalities are difficult to see or cannot be seen during the first trimester, such as cardiac tumors, complete heart block, cardiomyopathies, Ebstein's anomaly, aortic or pulmonary stenosis, and tricuspid atresia. ${ }^{38}$

It has been shown that there is a relationship between increased NT and fetal heart structure and function. ${ }^{39}$ Makrydimas et al conducted a pooled analysis among major fetal echocardiography centers which shows that NT of $\geq 3.5 \mathrm{~mm}$ may lead to an early diagnosis of all major CHDs. ${ }^{40}$ In fetuses with NT between the 95th and 99th percentile, the prevalence of cardiac defects is about $2 \%$. However, according to Atzei et al, increased NT is not an adequate screening marker for cardiac anomalies in euploid fetuses if it is isolated, because of the relatively low sensitivity $(30 \%){ }^{42}$

Additional markers that could be useful in detecting congenital heart diseases are tricuspid regurgitation (TR) and ductus venosus (DV). Many studies have shown that if NT is above the 95th percentile, TR or DV reversed a-wave were observed in $35.3 \%, 32.9 \%$, and $28.2 \%$ of the cases with major CHD, respectively, and in $4.8 \%, 1.3 \%$, and $2.1 \%$ of those without $\mathrm{CHD}$, respectively. ${ }^{43}$

Jelliffe-Pawlowski et al found, in 2011, an abnormal serum level of a-fetoprotein, hCG, and unconjugated estriol in the CHD group, but the value of first and second trimester maternal serum biochemical markers in screening for fetal CHDs remains to be determined. ${ }^{44}$

It is increasingly evident, therefore, that the detection of CHDs in the first trimester is feasible and it is more accurate by adding markers such as NT, TR, and DV reversed a-wave,

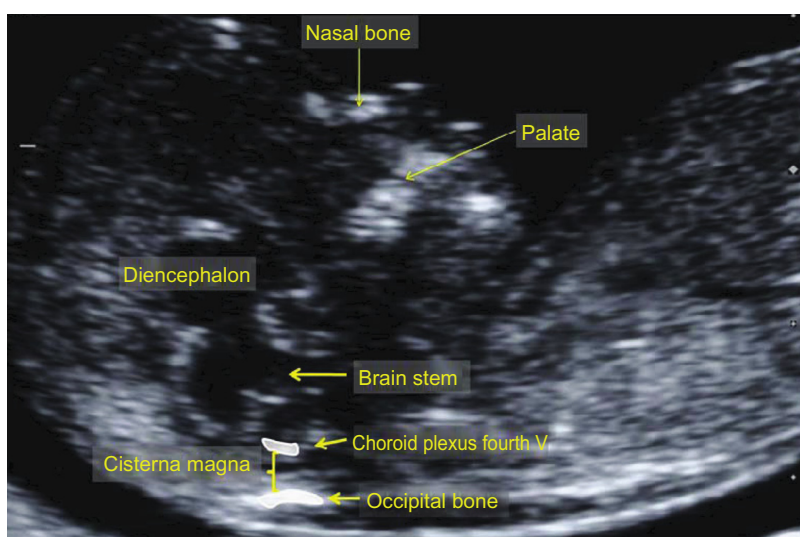

Figure 5 Mid-sagittal plane and the cisterna magna. but early echocardiography is still reserved for those cases considered at high risk for cardiac defects and must not be a routine examination.

\section{DV}

DV is a small high-flow vessel that connects the umbilical vein to the inferior vena cava. It switches and distributes oxygenated blood directly from the placenta to the right atrium, and its alteration has been related to congenital heart disease and chromosomal abnormalities.

It can be visualized and evaluated under specific criteria, on a mid-sagittal view of the fetal abdomen where it shows aliasing flow at Color Doppler (FMF website) (Figure 6).

Pulsed Doppler allows the study of the impedance of this vessel the impedance of this vessel's flow (pulsatility index $[\mathrm{PI}]$ ) and to characterize the a-wave as positive (normal), absent or reversed (reversed wave) (pathological). ${ }^{45}$ Since blood flow velocity in human fetal DV was described in 1991, its measurement has proved to be a reproducible method to study conditions such as fetal cardiac diseases, fetal growth restriction, red blood cell alloimmunization, and twin-to-twin transfusion syndrome. ${ }^{46}$

Initially reported as a pathological sign in the second and third trimester of pregnancy, reversed DV flow has been associated with chromosomally abnormal fetuses with increased NT in first trimester screening. ${ }^{47}$

In 2012, Maiz et al demonstrated that DV flow increases the detection rate for chromosomal abnormalities in the first trimester to about $96 \%$, reducing the false positive rate to $2.5 \%$, later confirmed also by Nicolaides with the introduction of the PI of DV. ${ }^{48}$

Martinez et al focused on the relation between the abnormal DV flow in the first trimester and CHD, defining it as an important marker for cardiac defects in fetuses with normal karyotype and normal NT. ${ }^{49}$

Papatheodorou et al, in a meta-analysis, assessed the screening performance of DV RW for detection of CHD: sensitivity was higher in a population of fetuses with increased NT than in a non-NT tested one or with normal NT; meanwhile, approximately $96 \%$ of fetuses with normal NT and no cardiac defects showed a normal DV waveform. ${ }^{50}$

Borrel et al demonstrated that combining DV RW with NT greater than 95 th percentile allows the detection of $58 \%$ of major cardiac defects with a $6.4 \%$ false positive rate and up to $47 \%$ for NT greater than 95 th percentile with a $2.7 \%$ false positive rate. ${ }^{51}$

Absence of DV or DV agenesis has been related to fetal anomalies like chromosomal aberrations and absence of the 


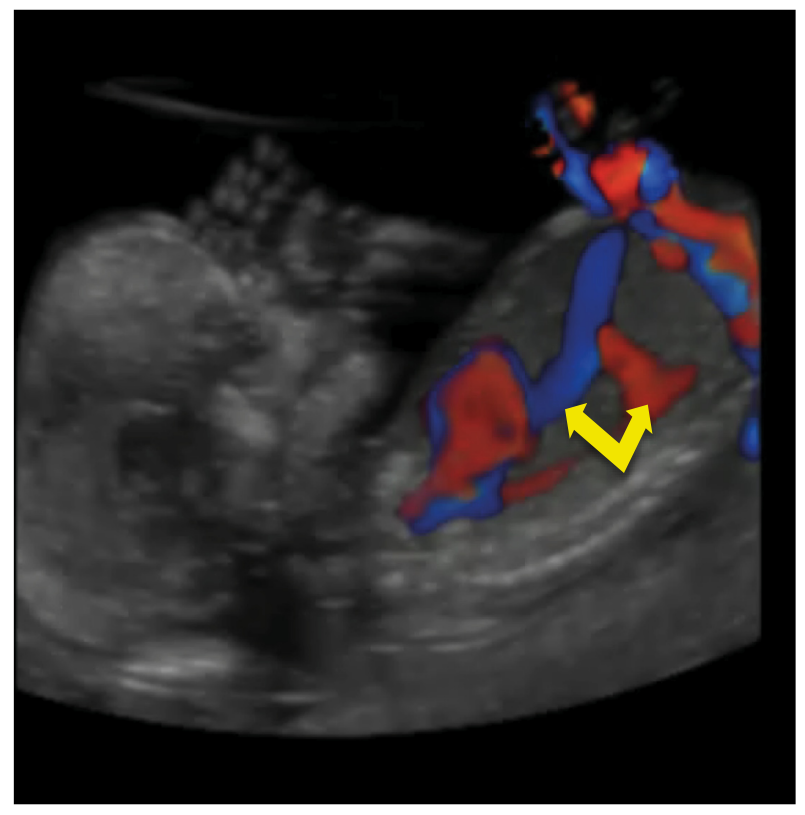

Figure 6 Ductus venosus and hepatic artery (arrows).

portal vein, and to adverse outcomes such as in utero heart failure. $^{52}$

In 2011, Staboulidou et al showed that $40 \%$ of fetuses with NT above the 95th centile and agenesis of DV had chromosomal abnormalities, while fetuses with NT below the 95th centile and absence of DV resulted in healthy live births. ${ }^{53}$ Berg et al confirmed the additional risk of liver bypass in fetuses with agenesis of DV: in the absence of other malformations, it could be associated with a worse prognosis because of congestive heart failure, even in the presence of normal cardiovascular anatomy, than in fetuses with DV agenesis without liver by-passing. ${ }^{54}$

\section{Tricuspid valve regurgitation}

TR is a condition causing backward blood flow into the right atrium during ventricular systole. In the last decades, it has been associated with chromosomal abnormalities and CHDs in euploid fetuses. ${ }^{55}$

The presence or absence of TR can be determined by pulsed-wave Doppler during fetal quiescence, positioning a gate of 2.0-3.0 $\mathrm{mm}$ above the valve in an apical four-chamber view under FMF criteria: TR is defined when there is a peak of velocity $>60 \mathrm{~cm} / \mathrm{s}$ (FMF website).

In 2006, Falcon et al examined the performance of a screening test that combines TR with fetal NT thickness, serum-free $\beta$-hCG, and PAPP-A, and demonstrated that the detection rate for trisomy 21 was $91 \%$ with $2.6 \%$ false positive rate. Furthermore, in another study they found TR in less than $5 \%$ of euploid fetuses, while it was present in more than $65 \%$ of fetuses with trisomy 21 and in more than $30 \%$ of those with trisomy $18 .{ }^{56}$ Kagan et al reported that algorithms for first trimester screening tests including TR increased the detection rate for trisomy 21 from $91 \%$ to $96 \%$ for the same false positive rate of $3 \%$, with simultaneous detection of nearly all cases of trisomy 18 , trisomy 13 , and Turner syndrome. ${ }^{57}$ Persico et al confirmed that TR was more commonly found in fetuses with chromosomal abnormalities and suggested that the prevalence of TR was higher in fetuses with cardiac defects than in those with normal hearts, regardless of fetal karyotype. ${ }^{58}$

TR has reached an important clinical relevance, creating the possibility for early prediction of major cardiac defects at 11-14 weeks. Pereira et al use this parameter in combination with NT and DV to improve the screening performance: on 45,191 singleton pregnancies where they found 85 cases of major CHD: NT above 95th centile, TR and DV reversed a-wave were observed in $35.3 \%, 32.9 \%$, and $28.2 \%$ of CHD cases and at a fixed false positive rate of $1 \%, 3 \%$, and $5 \%$, the detection rate for CHD was $36.5 \%, 48.2 \%$, and $54.1 \%$, respectively. ${ }^{59}$

\section{Aberrant right subclavian artery}

Aberrant right subclavian artery (ARSA) is an aortic arch anomaly characterized by the origin of the right subclavian artery from the descending aorta. Due to this origin, set on the left of the middle line, the right subclavian artery passes behind both the trachea and the esophagus to reach the right arm. In 2002, Yagel et al proposed a sonographic view to appreciate this altered vessel course, called "three vessels and tracheal view" (Figure 7) ${ }^{60}$

Postnatally, ARSA has been found to be related to congenital heart anomalies such as conotruncal anomalies, septal defects, obstructive anomalies of the left side of the heart, right heart anomalies, and Down syndrome $(12 \%){ }^{61}$

The relation between ARSA and Down syndrome has been further examined in many studies with discordant results: Chaoui et al in 2005, showed an incidence of ARSA increased in cases of trisomy 21 , with a percentage ranging between $29 \%$ and $37 \%$, but in 2008 Borenstein et al, who demonstrated the possibility to assess the course of the right subclavian artery in about $80 \%$ of cases by transabdominal ultrasound imaging at 11-14 weeks, found ARSA in only $8 \%$ of fetuses with trisomy 21 , suggesting it as a slightly useful marker of trisomy 21 in the first trimester. ${ }^{62,63}$ 
Paladini et al reported that the incidence of ARSA in Down syndrome fetuses is about $25 \%$ and demonstrated that this vessel can be independent from other sonographic signs of Down syndrome (such as nasal bone and NT), being the only sonographic sign in $7.5 \%$ of the cases. ${ }^{64}$

\section{Hepatic artery}

The hepatic artery (HA) arises in most fetuses from the celiac artery, and less frequently ( $18 \%$ of cases) from the superior mesenteric artery; the common HA branches off into the right, left, and middle HA. In first trimester fetuses, the HA is in close contact with the DV (Figure 2). After recording the DV waveform, in fact, the sample gate can be slightly moved toward the descending thoracic aorta so that HA waveforms can be visualized simultaneously on the reverse channel (Figure 6).

One study investigating normal fetuses reported that the HA peak systolic velocity (PSV) increases with gestation from a mean of $18 \mathrm{~cm} / \mathrm{s}$ at 21 weeks to $33 \mathrm{~cm} / \mathrm{s}$ at 38 weeks. ${ }^{65}$ This increase is probably due to the progressive development of arteries and intra-portal capillaries. ${ }^{66}$

It is known that, in fetal hypoxemia, the flow in HA increases in order to maintain blood supply to the liver when there is an increased shunting of umbilical venous blood through the DV. ${ }^{67}$ Low-resistance HA flow has been documented in second trimester growth-restricted fetuses: In 1999, Kilavuz and Vetter suggested that in cases of shunting of oxygenated umbilical venous blood through the DV, the total blood supply to the liver is maintained by a concomitant and significant increase in arterial blood flow through the HA. ${ }^{68}$

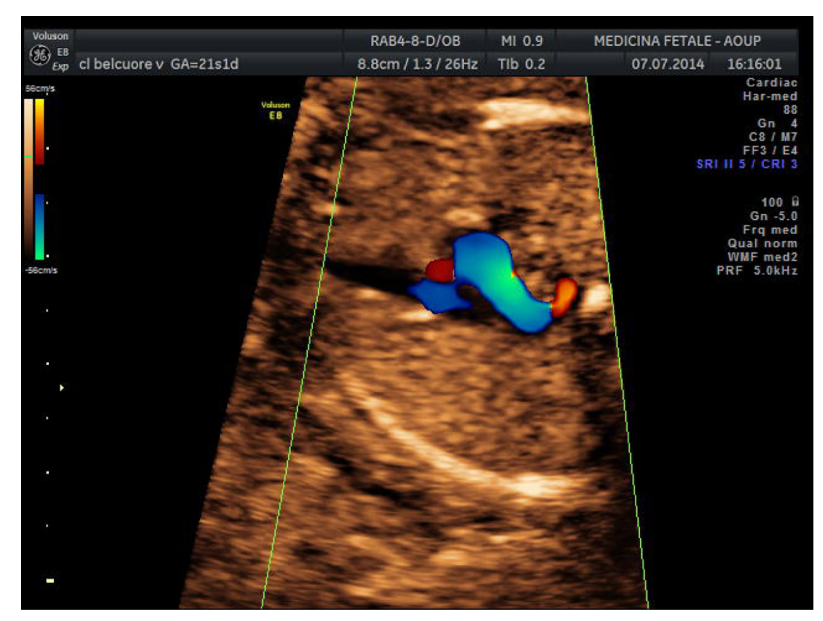

Figure 7 Aberrant right subclavian artery (ARSA).
Few studies investigating HA during the first trimester of pregnancy have been conducted: Zvanca et al, in 2011, demonstrated that in trisomy 21 fetuses, at 11-13 weeks, the fetal HA PSV is increased and PI is decreased, suggesting the presence of an increased number of arterioles or vasodilation in the branches of this vessel with concomitant increase in flow. They have also noticed that in both euploid and trisomic fetuses, high HA PSV is associated with TR and reversed a-wave in the DV. They suggested that examination of the HA could be undertaken in those women with an intermediate risk for trisomy 21, but a standard technique for the assessment of this vessel has yet to be determined. ${ }^{69}$

\section{Cervical length}

In this last decade, measurement of cervical length has become an important method to predict preterm delivery at 20-24 weeks of gestational age, especially thanks to the development of transvaginal probes. ${ }^{70}$

It has been shown that the use of vaginal progesterone in women with a short cervix reduces the rate of preterm birth by as much as $45 \%$, but it is not useful if cervical length is less than $10 \mathrm{~mm} .{ }^{71}$ Therefore, many studies have been conducted to evaluate the possibility of earlier detection of women at risk for preterm delivery even before 14 weeks of gestation, in order to reduce preterm delivery (PTD) incidence by promptly starting vaginal progesterone.

The first study reported that cervical length in the first trimester was not predictive of preterm delivery, probably due to the inaccurate cervix measurement before 14 weeks, which is not easily distinguishable from the lower uterine segment. ${ }^{72}$ However, in 2011, Greco et al proposed a new method for the measurement of cervical length in the first trimester of pregnancy, which reports that the median lengths of the cervix and the cervico-isthmic complex at 11-13 weeks were $32 \mathrm{~mm}$ and $45 \mathrm{~mm}$ respectively: they noticed that the cervico-isthmic complex length was the same between women who delivered before and after 34 weeks, while the endocervical length was shorter in those women with PTD. ${ }^{73}$ Souka et al showed that the same method can be used to predict PTD even before 32 weeks of gestational age. ${ }^{74}$ More recently, in 2012, Greco et al suggested an algorithm, combining maternal characteristics and cervical length, which identified about $55 \%$ of pregnancies resulting in delivery before 34 weeks, at a false positive rate of $10 \%$ and a detection rate for delivery at 34-36 weeks that was only $20 \% .^{75}$

These studies demonstrate that it might be possible to predict PDT as early as the first trimester of pregnancy, but further research should be undertaken. 


\section{Conclusion}

Obstetricians always aspire to promote the birth of healthy children, and reduce childbirth complications and perinatal mortality.

For this purpose, antenatal ultrasound has become ever more important and the first trimester and is now considered the moment at which a specific risk for pregnancy can be detected.

The worldwide testing for Down syndrome risk favored, in turn, the intensification of screening for other fetal conditions and from the 1980s; prenatal care had begun to focus on the fetus.

In 2013, the International Society of Ultrasound in Obstetrics and Gynecology looked at its practice guidelines for performance of first trimester ultrasound:

The purpose of the first trimester fetal ultrasound includes not only the chorionicity and amnionicity in number of fetuses, but to detect gross fetal malformations and it should be performed between 11 and 14 weeks gestation. ${ }^{76}$

Considering this words, fetal structures already developed at this time of pregnancy should be seen during first trimester ultrasound and the presence of major malformations should be recognized. High-frequency transducers have improved the study of fetus anatomy, but it may require a previous knowledge of embryology to understand a normal development. Therefore, according to the literature, it is clear that fetal anatomy is recognizable on a first trimester scan even if certain structures may not be fully developed, and the second trimester scan remains important.

A new era for prenatal diagnosis was "born" with the introduction of cell-free DNA for non-invasive prenatal testing, ${ }^{77}$ but the need to enhance our imaging capacities is rising because the role of the nuchal scan will not only be to identify chromosomal anomalies, but to identify a pregnancy with other specific risks.

In this review, it has been shown how characteristic fetal landmarks in the first trimester are proven to be related not only to chromosomal anomalies, but also to structural defects like cardiovascular ones, developing brain injuries, syndromic diseases, and to pregnancy complications like preeclampsia and preterm birth (Table 1).

At this point, ultrasound assessment of fetal anatomy should be an obligation for those operators performing first trimester scans, keeping in mind ethical, logical, and practical approaches to early pregnancy also considering the right to choose to discontinue an affected pregnancy.
Considering the time-money for the social cost, this approach could be initially expensive, but with the increasing several operators' experience, subtle anatomical changes could lead to identification of a problem and its possible solution.

Surely, a training program and a detailed examination protocol that ensures a systematic approach must be constructed for operators, but together, the use of an increased quality ultrasound machine, a skilled obstetrician will finally have the opportunity to improve fetal medicine and to reduce perinatal morbidity and mortality.

\section{Acknowledgment}

I want to thank my collaborators for their precious help with this review: Irene Carpita, Carla Vaccaro, Laura Angeli, and the Unit Director Angiolo Gadducci.

\section{Disclosure}

The author has no conflicts of interest to disclose.

\section{References}

1. Nicolaides KH. A model for a new pyramid of prenatal care, based on the 11-13 weeks' assessment. Prenat Diagn. 2011;31(1):3-6.

2. Borrell A, Grande M, Bennasar M, et al. First-trimester detection of major cardiac defects with use of ductus venosus blood flow. Ultrasound Obstet Gynecol. 2013;42(1):51-57.

3. Luchi C, Schifano M, Sacchini C, et al. Detailed fetal anatomy assessment in the first-trimester at 11,12 and 13 weeks of gestation. J Matern Fetal Neonatal Med. 2012;25(6):675-678.

4. Ghi T, Pilu G, Savelli L, Segata M, Bovicelli L. Sonographic diagnosis of Congenital anomalies during the first trimester. Placenta. 2003; 24 Suppl B:S84-S87.

5. Gorlin RJ, Cervenka J, Pruzansky S. Facial clefting and its syndromes. Birth Defects Orig Artic Ser. 1971;7(7):3-49.

6. Stoll C, Alembik Y, Dott B, Roth MP. Associated malformations in cases with oral clefts. Cleft Palate Craniofac J. 2000;37(1):41-47.

7. Sepulveda W, Wong AE, Martinez-Ten P, Perez-Pedregosa J. Retronasal triangle: a sonographic landmark for the screening of cleft palate in the first trimester. Ultrasound Obstet Gynecol. 2010;35(1):7-13

8. Martinez-Ten P, Adiego B, Illescas T, Bermejo C, Wong AE, Seulveda W. First trimester diagnosis of cleft lip and palate using three-dimensional ultrasound. Ultrasound Obstet Gynecol. 2012;40(1):40-46.

9. Sepulveda W, Wong AE, Vinals F, Andreeva E, Adzehova N, Martinez-Ten P. Absent mandibular gap in the retronasal triangle view: a clue to the diagnosis of micrognathia in the first trimester. Ultrasound Obstet Gynecol. 2012;39(2):152-156.

10. Gardner E, O'Rahilly R, Prolo D. The Dandy-Walker and Arnold-Chiari malformations. Arch Neurol. 1975;32(6):393-407.

11. Nicolaides KH, Campbell S, Gabbe SG, Guidetti R. Ultrasound screening for spina bifida: cranial and cerebellar signs. Lancet. 1986;2(8498):72-74.

12. Van den Hof MC, Nicolaides KH, Campbell J, Campbell S. Evaluation of the lemon and banana signs in one hundred and thirty fetuses with open spina bifida. Am J Obstet Gynecol. 1990;162(2): $322-327$. 
13. Ghi T, Pilu G, Falco P, et al. Prenatal diagnosis of open and closed spina bifida. Ultrasound Obstet Gynecol. 2006;28(7):899-903.

14. Chaoui R, Benoit B, Mitkowska-Wozniak H, Heling KS, Nicolaides KH. Assessment of intracranial translucency (IT) in the detection of spina bifida at the 11-13-week scan. Ultrasound Obstet Gynecol. 2009;34(3):249-252.

15. Lachmann R, Chaoui R, Moratalla J, Picciarelli G, Nicolaides KH Posterior brain in fetuses with open spina bifida at 11 to 13 weeks. Prenat Diagn. 2011;31(1):103-106.

16. Bernard JP, Cuckle HS, Stirnemann JJ, Salomon LJ, Ville Y. Screening for fetal spina bifida by ultrasound examination in the first trimester of pregnancy using fetal biparietal diameter. Am J Obstet Gynecol. 2012;207(4):306. e1-e5.

17. Loureiro T, Ushakov F, Montenegro N, GielchinckyY, Nicolaides KH. Cerebral ventricular system in fetuses with open spina bifida at 11-13 weeks' gestation. Ultrasound Obstet Gynecol. 2012;39(6):620-624.

18. Chen M, Lee CP, Lam YH, et al. Comparison of nuchal and detailed morphology ultrasound examinations in early pregnancy for fetal structural abnormality screening: a randomized controlled trial. Ultrasound Obstet Gynecol. 2008;31(2):136-146.

19. Sepulveda W, Dezerega V, Be C. First-trimester sonographic diagnosis of holoprosencephaly: value of the "butterfly" sign. J Ultrasound Med. 2004;23(6):761-765.

20. Luchi C, Monacci F, Schifano M, Gadducci A. 'Bat-like' choroid plexus and other sonographic features in trisomy 22 at the first trimester of pregnancy. Prenat Diagn. 2013;33(10):1013-1014.

21. Bronshtein M, Ben-Shlomo I. Choroid plexus dysmorphism detected by transvaginal sonography: the earliest sign of fetal hydrocephalus. J Clin Ultrasound. 1991;19(9):547-553.

22. Pooh RK. Imaging diagnosis of congenital brain anomalies and injuries Semin Fetal Neonatal Med. 2012;17(6):360-376.

23. Seligman NS. Ultrasound for Fetal Ventriculomegaly: Review Article. Ultrasound Clinics. 2013;8(1):13-25.

24. Kurjak A, Kupesic S, Matijevic R, Kos M, Marton Ulla. First Trimester malformation screening. European Journal of Obstetrics and Gynecology and Reproductive Biology. 1999;85(1):93-96.

25. van Zalen-Sprock RM, Van Vugt JM, Van Geijn HP. First and second trimester diagnosis of anomalies of the central nervous system. J Ultrasound Med. 1995;14(8):603-610.

26. Loureiro T, Ushakov F, Montenegro N, Nicolaides KH. Lateral ventricles in fetuses with aneuploidies at 11-13 weeks' gestation. Ultrasound Obstet Gynecol. 2012;40(3):282-287.

27. Khairy MA, Shazly SA, Ali H, AbdelbadeeAY, Abbas AM Ultrasonographic soft markers of aneuploidy in the second-trimester fetuses. Middle East Fertility Society Journal. 2012;17(3): $145-151$.

28. Garcia-Posada R, Eixarch E, Sanz M, Puerto B, Figueras F, Borrell A. Cisterna magna width at 11-13 weeks in the detection of posterior fossa anomalies. Ultrasound Obstet Gynecol. 2013;41(5):515-520.

29. Mensah GA, Brown DW. An overview of cardiovascular disease burden in the United States. Health Aff (Millwood). 2007;26(1):38-48.

30. Hoffman JI. Incidence of congenital heart disease: II. Prenatal incidence. Pediatr Cardiol. 1995;16(4):155-165.

31. Nicolaides KH. A model for a new pyramid of prenatal care, based on the 11-13 weeks' assessment. Prenat Diagn. 2011;31(1):3-6.

32. Rasiah SV, Publicover M, Ewer AK, Khan KS, Kilby MD, Zamora J. A systematic review of the accuracy of first-trimester ultrasound examination for detecting major congenital heart disease. Ultrasound Obstet Gynecol. 2006;28(1):110-116.

33. Volpe P, Ubaldo P, Volpe N, et al. Fetal cardiac evaluation at 11-14 weeks by experienced obstetricians in a low-risk population. Prenat Diagn. 2011;31(11):1054-1061.

34. Simpson JM, Jones A, Callaghan N, Sharland GK. Accuracy and limitations of transabdominal fetal echocardiography at 12-15 weeks of gestation in a population at high risk for congenital heart disease. BJOG. 2000;107(12):1492-1497.
35. Westin M, Saltvedt S, Bergman G, et al. Routine ultrasound examination at 12 or 18 gestational weeks for prenatal detection of major congenital heart malformations? A randomised controlled trial comprising 36,299 fetuses. BJOG. 2006;113(6):675-682.

36. Kahil A, Nicholaides KH. Fetal heart defects: Potential and pitfalls of firsttrimester detection. Semin Fetal Neonatal Med. 2013;18(5):251-260.

37. Syngelaki A, Chelemen T, Dagklis T, Allan L, Nicolaides KH. Challenges in the diagnosis of fetal non-chromosomal abnormalities at 11-13 weeks. Prenat Diagn. 2011;31(1):90-102.

38. Allan L, Cook A, Huggon I. First trimester fetal heart scanning. In: Allan L, Cook A, Huggon I, editors. Fetal Echocardiography a Practical Guide. New York: Cambridge University Press; 2009:190-202.

39. Clur SA, Ottenkamp J, Bilardo CM. The nuchal translucency and the fetal heart: a literature review. Prenat Diagn. 2009;29(8):739-748.

40. Makrydimas G, Sotiriadis A, Hugon IC, et al. Nuchal translucency and fetal cardiac defects: a pooled analysis of major fetal echocardiography centers. Am J Obstet Gynecol. 2005;192(1):89-95.

41. Snijders RJ, Noble P, Sebire NJ, Souka AP, Nicolaides KH. UK multicentre project on assessment of risk of trisomy 21 by maternal age and fetal nuchaltranslucency thickness at 10-14 weeks of gestation. Fetal Medicine Foundation First Trimester Screening Group. Lancet. 1998;352(9125):343-346.

42. Atzei A, Gajewska K, Huggon IC, Allan L, Nicolaides KH. Relation between nuchal translucency thickness and prevalence of major cardiac defects in fetuses with normal karyotype. Ultrasound Obstet Gynecol. 2005;26(2):154-157.

43. Pereira S, Ganapathy R, Syngelaki A, Maiz N, Nicolaides KH. Contribution of fetal tricuspid regurgitation in first-trimester screening for major cardiac defects. Obstet Gynecol. 2011;117(6):1384-1391.

44. Jelliffe-Pawlowski L, Baer R, Moon-Grady AJ, Currier RJ. Second trimester serum predictors of congenital heart defects in pregnancies without chromosomal or neural tube defects. Prenat Diagn. 2011;31(5):466-472.

45. Montenegro N, Matias A, Arejas JC, Barros H. Ductus venosus revisited: a Doppler blood flow evaluation in the first trimester of pregnancy. Ultrasound Med Biol. 1997;23(2):171-176.

46. Kiserud T, Stratford L, Hanson JA. Umbilical flow distribution to the liver and the ductus venosus: An in vitro investigation of the fluid dynamic mechanisms in the fetal sheep. Am J Obstet Gynecol. 1997; 177(1):86-90.

47. Matias A, Gomes C, Flack N, Montenegro N, Nicolaides KH. Screening for chromosomal abnormalities at 10-14 weeks: the role of ductus venosus blood flow. Ultrasound Obstet Gynecol. 1998;12(6):380-384.

48. Maiz N, Wright D, Ferreira AF, Syngelaki A, Nicolaides KH. A mixture model of ductus venosus pulsatility index in screening of aneuploidies at 11-13 weeks' gestation. Fetal Diagn Ther. 2012;31(4):221-229.

49. Martinez JM, Comas M, Borrell A, et al. Abnormal first-trimester ductus venosus blood flow: a marker of cardia defects in fetuses with normal karyotype and nuchal translucency. Ultrasound Obstet Gynecol. 2010;35(3):267-272.

50. Papatheodorou SI, Evangelou E, Makrydimas G, Ioannidis JP. First-trimester ductus venosus screening for cardiac defects: a metaanalyses. BJOG. 2011;118(12):1438-1445.

51. Borrell A, Grande M, Bennasar M, et al. First-trimester detection of major cardiac defects with use of ductus venosus blood flow. Ultrasound Obstet Gynecol. 2013;42(1):51-57.

52. Contratti G, Banzi C, Ghi T, Perolo A, Pilu G, Visentin A. Absence of the ductus venosus: report of 10 new cases and review of the literature. Ultrasound Obstet Gynecol. 2001;18(6):605-609.

53. Staboulidou I, Pereira S, Cruz Jde J, Syngelaki A, Nicolaides KH. Prevalence and outcome of absence of ductus venosus at $11(+0)$ to 13 (+6) weeks. Fetal Diagn Ther. 2011;30(1):35-40.

54. Berg C, Kamil D, Geipel A, et al. Absence of ductus venosus-importance of umbilical venous drainage site. Ultrasound Obstet Gynecol. 2006;28(3):275-281.

55. Kagan KO, Valencia C, Livanos $P$, Wright $D$, Nicolaides KH. Tricuspid regurgitation in screening for trisomies 21, 18 and 13 and Turner syndrome at $11+0$ to $13+6$ weeks of gestation. Ultrasound Obstet Gynecol. 2008;33(1):18-22. 
56. Falcon O, Faiola S, Huggon I, Allan L, Nicolaides KH. Fetal tricuspid regurgitation at the $11+0$ to $13+6$-week scan: association with chromosomal defects and reproducibility of the method. Ultrasound Obstet Gynecol. 2006;27(6):609-612.

57. Kagan KO, Valencia C, Livanos P, Wright D, Nicolaides KH. Tricuspid regurgitation in screening for trisomies 21, 18 and 13 and Turner syndrome at $11+0$ to $13+6$ weeks of gestation. Ultrasound Obstet Gynecol. 2008;33(1):18-22.

58. Persico N, Moratalla J, Lombardi CM, Zidere V, Allan L, Nicolaides KH. Fetal echocardiography at 11-13 weeks by transabdominal high-frequency ultrasound. Ultrasound Obstet Gynecol. 2011;37(3):296-301.

59. Pereira S, Ganapathy R, Syngelaki A, Maiz N, Nicolaides KH. Contribution of fetal tricuspid regurgitation in first-trimester screening for major cardiac defects. Obstet Gynecol. 2011;117(6):1384-1391.

60. Yagel S, Arbel R, Anteby EY, Raveh D, Achiron R. The three vessels and trachea view (3VT) in fetal cardiac scanning. Ultrasound Obstet Gynecol. 2002;20(4):340-345.

61. Zapata H, Edwards JE, Titus JL. Aberrant right subclavian artery with left aortic arch: associated cardiac anomalies. Pediatr Cardiol. 1993;14(3):159-161.

62. Chaoui R, Thiel G, Heling KS. OC29.02: Prevalence of an aberrant right subclavian artery (ARSA) in normal fetuses: a new soft marker for trisomy 21 risk assessment. Ultrasound Obstet Gynecol. 2005;26(4):356.

63. Borenstein M, Cavoretto P, Allan L, Huggon I, Nicolaides KH. Aberrant right subclavian artery at $11+0$ to $13+6$ weeks of gestation in chromosomally normal and abnormal fetuses. Ultrasound Obstet Gynecol. 2008;31(1):20-24.

64. Paladini D, Sglavo G, Pastore G, Masucci A, D’Armiento MR, Nappi C. Aberrant right subclavian artery: incidence and correlation with other markers of Down sydrome in second trimester fetuses. Ultrasound Obstet Gynecol. 2012;39(2):191-195.

65. Ebbing C, Rasmussen S, Godfrey KM, Hanson MA, Kiserud T. Hepatic artery hemodynamics suggest operation of a buffer response in the human fetus. Reprod Sci. 2008;15(2):166-178.

66. Gouysse G, Couvelard A, Frachon S, et al. Relationship between vascular development and vascular differentiation during liver organogenesis in humans. J Hepatol. 2002;37(6):730-740.
67. Ebbing C, Rasmussen S, Godfrey KM, Hanson MA, Kiserud T. Hepatic artery hemodynamics suggest operation of a buffer response in the human fetus. Reprod Sci. 2008;15(2):166-178.

68. Kilavuz O, Vetter K. Is the liver of the fetus the 4 th preferential for arterial blood supply besides brain, heart, and adrenal glands? J Perinat Med. 1999;27(2):103-106.

69. Zvanca M, Gielchinsky Yuval, Abdeljawad F, Bilardo CM, Nicolaides KH. Hepatic artery Doppler in trisomy 21 and euploid fetuses at 11-13 weeks. Prenat Diagn. 2011;31(1):22-27.

70. Iams JD, Goldenberg RL, Meis PJ, et al. The length of the cervix and the risk of spontaneous premature delivery. National Institute of Child Health and Human Development Maternal Fetal Medicine Unit Network. N Engl J Med. 1996;334(9):567-572.

71. Fonseca EB, Celik E, Parra M, Singh M, Nicolaides KH, Fetal Medicine Foundation Second Trimester Screening Group. Progesterone and the risk of preterm birth among women with a short cervix. $N$ Engl J Med. 2007;357(5):462-469.

72. Mella MT, Berghella V. Prediction of preterm birth: cervical sonography. Semin Perinatol. 2009;33(5):317-324.

73. Greco E, Lange A, Ushakov F, Calvo JR, Nicolaides KH. Prediction of spontaneous preterm delivery from endocervical length at 11 to 13 weeks. Prenat Diagn. 2011;31(1):84-89.

74. Souka AP, Papastefanou I, Michalitsi V, Papadopoulos GK, Kassanos D. A predictive model of short cervix at 20-24 weeks using first-trimester cervical length measurement and maternal history. Prenat Diagn. 2011;31(2):202-206.

75. Greco E, Gupta R, Syngelaki A, Poon LC, Nicolaides KH. First-Trimester Screening for Spontaneous Preterm Delivery with Maternal Characteristics and Cervical Length. Fetal Diagn Ther. 2012; 31(3):154-161.

76. Salomon LJ, Alfirevic Z, Bilardo CM, et al. ISUOG Practice Guidelines: performance of first-trimester fetal ultrasound scan. Ultrasound Obstet Gynecol. 2013;41(1):102-113.

77. Benn P, Cuckle H, Pergament E. Non-invasive prenatal testing for aneuploidy: current status and future prospects. Ultrasound Obstet Gynecol. 2013;42(1):15-33.
Research and Reports in Neonatology

\section{Publish your work in this journal}

Research and Reports in Neonatology is an international, peer-reviewed, open access journal publishing original research, reports, editorials, reviews and commentaries on neonatal health. The manuscript management system is completely online and includes a very quick and fair
Dovepress

peer-review system. Visit http://www.dovepress.com/testimonials.php to read real quotes from published authors. 